\title{
In Silico of Different Gait Cycle in Customised Leg Orthosis: A Finite Element Approach
}

Ahmad Amirul Faiz Mamat Hazri' ${ }^{1,2}$, Amir Mustakim Ab Rashid ${ }^{1,2}$, Abdul Halim Abdullah³, Ng Bing Wui, Ahmad Kafrawi Nasution 5 , Gan Hong Seng ${ }^{6}$ and Muhammad Hanif Ramlee ${ }^{1,2^{*}}$

${ }^{1}$ Medical Devices and Technology Centre (MEDiTEC), Institute of Human Centered Engineering (iHumEn), Universiti Teknologi Malaysia, 81310 UTM Johor Bahru, Johor, Malaysia

${ }^{2}$ Bioinspired Device and Tissue Engineering (BIOINSPIRA) Research Group, School of Biomedical Engineering and Health Sciences, Faculty of Engineering, Universiti Teknologi Malaysia, 81310 UTM Johor Bahru, Johor, Malaysia

${ }^{3}$ Faculty of Mechanical Engineering, Universiti Teknologi MARA (UiTM), 40450 Shah Alam, Selangor, Malaysia

${ }^{4}$ Department of Orthopaedics, Hospital Pakar Kanak-Kanak, Universiti Kebangsaan Malaysia, 56000 Kuala Lumpur, Malaysia

${ }^{5}$ Department of Mechanical Engineering, Faculty of Engineering, Muhammadiyah University of Riau, Pekanbaru, Indonesia

${ }^{6}$ British Malaysia Institute, Universiti Kuala Lumpur (UniKL), Batu 8, Jalan Sungai Pusu, 53100 Gombak, Selangor, Malaysia

\begin{abstract}
Leg orthosis is one of medical device for fracture bone treatment. Several complications have been reported when patients are wearing the conventional Plaster of Paris or fibreglass leg orthosis. Its including numbness due to tight application, swelling, venous congestion and skin irritation. Therefore, the aim of this study is to develop and biomechanical analyse a customised leg cast that could tackle those complications. First, the leg was scanned using a $3 \mathrm{D}$ scanner. The leg cast was constructed from a $3 \mathrm{D}$ scanned leg model and designed using 3-Matic software which later simulated in finite element analysis using Marc software. The study focuses on three gait cycles; midstance, heel strike and toe off where stress and deformation were predicted. From the results, the cast only supported the ankle in midstance phase with only 7.297MPa stress and not capable to support the ankle in heel strike and toe off phases with maximum stress of 106.99 $\mathrm{MPa}$ and $213.12 \mathrm{MPa}$, respectively, which are beyond its yield strength of $\mathrm{ABS}$, 23MPa. The average of overall displacement occurred for both skin and cast were less than $1.5 \mathrm{~mm}$. In short, the cast could only support the ankle in midstance phase and cannot be used for heel strike.
\end{abstract}

Keywords: leg orthosis; 3D modelling; finite element analysis; gait study

\section{INTRODUCTION}

Traumatic injury is always suddenly occurred in which required immediate medical attention. It can be caused by many mechanisms due to high forces from external bodies that exerted to human body and most of the incident were associated with ligaments injury (Standring et al., 2009). Due to that, bone fracture may occur that come along with many other complications (i.e., infections and misalignment) that need surgical attention by medical doctor. An ankle fracture could be happened when the joint is forced over its normal range of motion or caused by a direct hit to the bone itself. Any form of ankle trauma may lead to injury such as bone dislocation or fractures. Such situations are possibly occurred during foul play in sports, crash falling from a high ground or vehicle accidents that could severely injured the ankle (Scott et al., 2010). Therefore, medical physicians and surgeons would go for several devices to treat these injuries, which includes the orthosis (i.e., cast and splint), internal fixation (i.e., plates and screws) and external fixator (Singh et al.,

*Corresponding author's e-mail: muhammad.hanif.ramlee@biomedical.utm.my 
2014). For a less severe fracture, the casting method would be the best as a temporary limb immobilise. According to Singh. $\mathrm{R}$ et al. ankle fractures were happened as frequent as up to 107 and 184 per 100, ooo individuals annually (Singh et al., 2014). America alone set up to 260 ooo cases of ankle fracture every year (Scott et al., 2010). The common treatment for this ankle fractures is the usage of Plaster of Paris cast which were introduced as early in the $10^{\text {th }}$ century (Graham et al., 2018).

The leg orthosis or cast is a quick non-operative application that could provide positive result if the anatomical reduction is properly maintained (Scott et al., 2010). The orthosis device is meant to ensure the fracture bone could undergo healing process. By maintaining the position of fracture bone via installing orthosis at the human's limb, it can help the process of anatomical reduction. Unfortunately, the usage of current conventional cast often led to few complications throughout the recovery period (Singh et al., 2014). This possibly could be happened because of the conventional way of preparing the orthosis which is directly wrapping the limb together with the layers of Plaster of Paris. The negative effects include skin irritation and cutaneous complications as reported by previous study (Graham et al., 2018). A study was conducted by Ekwall A. et al. where they found out from a number of 403 patients in the emergency unit, about 111 patients suffered minor complications including swollen, bad fitting and numbness (Ekwall et al., 2018). To overcome the abovementioned problems, therefore, several studies have been done by many researchers to develop a new method of medical casting by implementing the $3 \mathrm{D}$ printing technologies (Zhang et. al., 2017; Evill et. al., 2013; Dal Maso et. al., 2019; Choo et. al., 2020; Xu et. al., 2019, Lal et al., 2018).

One of the factors that could contribute to faster bone healing is a micromovement integrity at the fracture site (Ramlee et al., 2015). Optimum micromovement could be achieved by installing stable fixation devices. Therefore, the orthosis should be able to support walking movement during rehabilitation period which mainly consists of two main phases in a gait cycle: swing and stance phase. However, the biomechanical stability of these orthoses has not been well investigated. Furthermore, there is no clear evidence in the present literature regarding whether these orthoses could produce the adequate stability and strength in treating ankle fractures and could support for different gait cycles such as midstance, heel strike and toe off. Therefore, the overall aim of this study was to evaluate the biomechanical analysis of leg orthosis in different gait conditions. Finite element method was used to assess the von Mises stress (VMS) distribution of the orthosis in the aforementioned three gaits to highlight the likelihood of the particular areas of the orthosis and foot that maybe subjected to excessive mechanical stress. This study also investigated the overall displacement in the orthosis and foot which indicating the stability of the cast.

\section{MATERIALS AND METHOD}

In this study, three main processes have been conducted. It includes three-dimensional (3D) scanning, 3D modelling and finite element modelling and analysis. Figure 1 shows the framework of research study design of the paper.

\section{Subject Recruitment}

\section{A subject was selected}

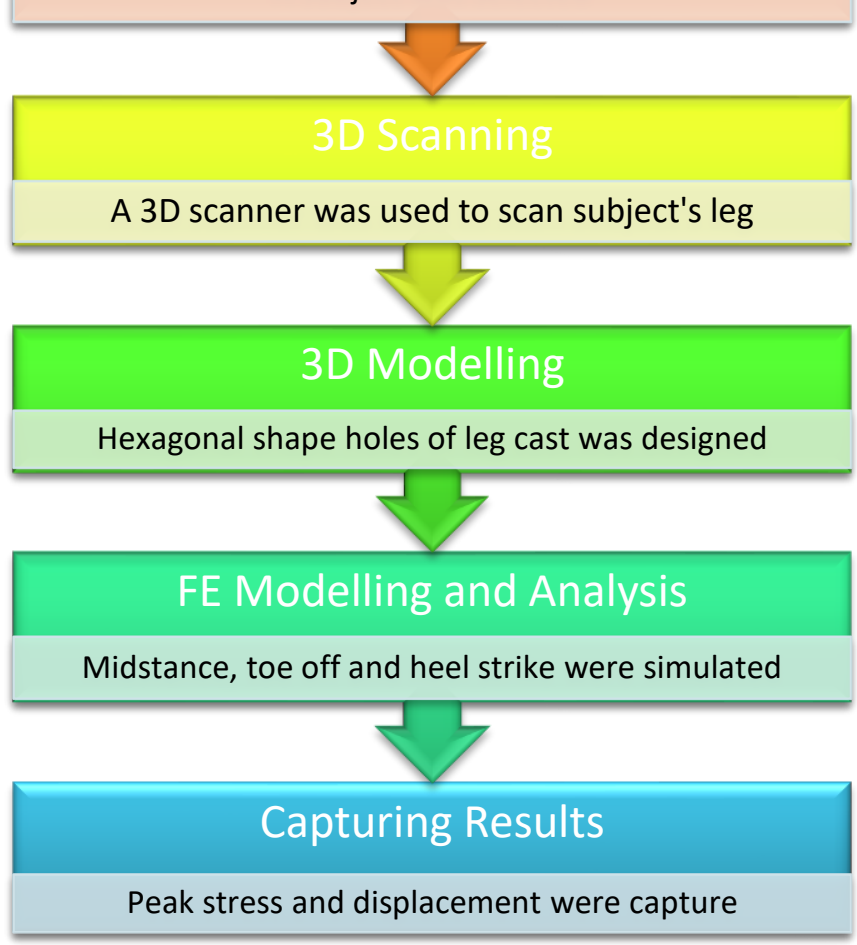

Figure 1. Framework of research study design

\section{A. 3 D Scanning}

A three-dimensional leg was obtained using Sense $^{\mathrm{TM}}{ }_{3 \mathrm{D}}$ Scanner (3D Systems, Netherland) as shown in Figure 2. The 3D model later was imported in the stereolithography (STL) 
format to a Computer Aided Design (CAD) software, 3-matic Medical (Materialiase, Belgium) for reconstruction of the surface geometry and realignment of the model. From here, all the noises or distortions on the model were removed to create an optimum defined leg model. The model was only considered part from part of tibia until the toes.

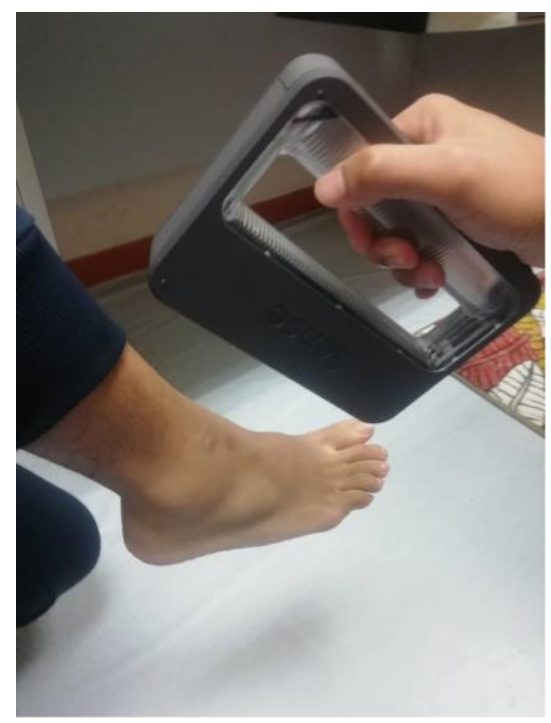

Figure 2. Leg scanning in the progress using 3D scanner (Sense)

\section{B. 3D Modelling}

From the $3 \mathrm{D}$ surface of leg (raw data from the $3 \mathrm{D}$ scanner system), a leg cast was designed using 3-matic Medical software. The thickness of the cast was set at $5 \mathrm{~mm}$ where a gap of $2 \mathrm{~mm}$ was set in between cast and the skin. The reason for the introduction of small gap is to allow the natural body contraction and expansion that happened, where those are part of the homeostasis or the temperature and fluidic regulations (Cheung, et al., 2005). The customised design was with hexagonal shaped holes as shown in Figure 3. The dimension of the leg cast was set to $170 \mathrm{~mm}, 200 \mathrm{~mm}$ and 102 $\mathrm{mm}$ in length, height and width, respectively. The hexagonal geometry ( $8 \mathrm{~mm}$ each side) was proposed for the holes. A previous study reported that the best geometry is hexagonal shape when structural strength is needed ( $\mathrm{Bu}$ et al., 2019). With this proposed design, a total of 72 hexagonal holes were designed in the $3 \mathrm{D}$ model of leg cast. On top of that, a ground plate with dimension of $250 \mathrm{~mm} \times 190 \mathrm{~mm} \times 10 \mathrm{~mm}$ was also constructed and this will be used for the finite element analysis in a later step. All models were then saved in STL format for the next processes.

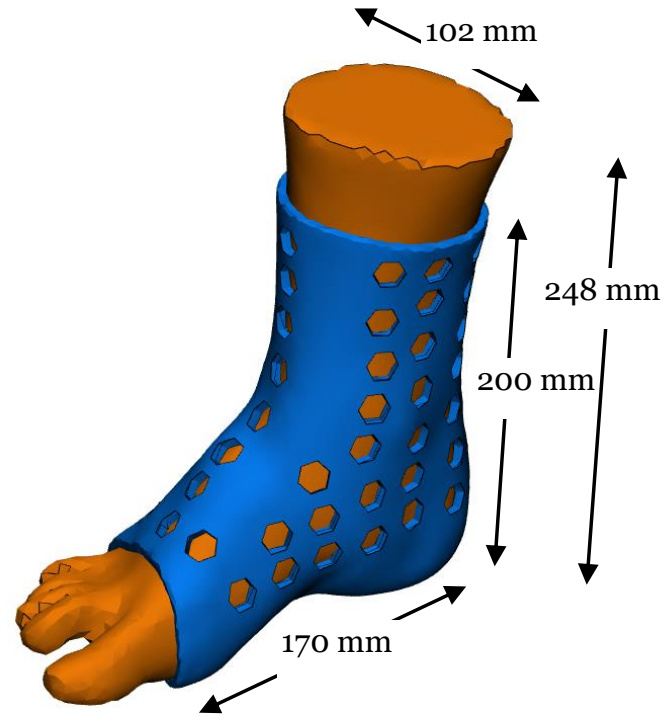

Figure $3 \cdot 3 \mathrm{D}$-designed leg cast with hexagonal holes

\section{Finite Element Modelling and Analysis}

The meshing size of the leg, cast and ground plate were set at $7 \mathrm{~mm}, 5 \mathrm{~mm}$ and $8 \mathrm{~mm}$, respectively, by applying adaptive meshing tool in the 3-matic software (Cheung et al., 2005). Later, the models were converted into tetrahedral volume mesh. Then, the $3 \mathrm{D}$ models were analysed through finite element method. All files were then imported in Marc Mentat (MSC. Software, CA). In this simulation, the models were set in isotropic, linear and homogeneous material properties. Table 1 shows all the values of Young 's modulus and Poisson 's ratio of all the meshed bodies. Also included in the table is the coefficient of friction between contact bodies. Glued interaction was set to bond the cast and skin while for cast and plate, it was set to touch condition.

In order to simulate human walking conditions, three gaits were used in this study; 1) midstance, 2) heel strike and 3) toe off, as shown in Figure 4. The body weight of the subject was assumed at $70 \mathrm{~kg}$. For the midstance phase, half of the body weight (BW) was applied as the load on the leg (Guo et al., 2009). While for heel strike and toe off, the load was 2.25BW and 3.oBW, respectively (Guo et al., 2009). The angle of heel strike was $30^{\circ}$ while for toe off, the angle was $25^{\circ}$ based on a previous study (Omasta et al., 2012). All loads were applied on the proximal leg model and the plate was fixed in all degree of freedom. The output from the simulation were in the form of contour plots that show the distribution of von Mises stress and overall displacement on the cast and skin. 
Table 1. Mechanical properties of meshed bodies

\begin{tabular}{|c|c|c|c|}
\hline Properties & Body & Value & Ref \\
\hline \multirow{3}{*}{$\begin{array}{l}\text { Young 's } \\
\text { modulus }\end{array}$} & $\begin{array}{c}\text { Orthosis } \\
\text { (ABS) }\end{array}$ & $3.1 \mathrm{GPa}$ & $\begin{array}{l}\text { Rohringer } \\
\text { et al., } \\
2019\end{array}$ \\
\hline & Skin & $20 \mathrm{MPa}$ & $\begin{array}{l}\text { Pawlaczyk } \\
\text { et al., } \\
2013\end{array}$ \\
\hline & $\begin{array}{c}\text { Ground } \\
\text { Plate }\end{array}$ & $17 \mathrm{GPa}$ & $\begin{array}{l}\text { Cheung et } \\
\text { al., } 2005\end{array}$ \\
\hline \multirow{3}{*}{$\begin{array}{l}\text { Poisson 's } \\
\text { Ratio }\end{array}$} & $\begin{array}{c}\text { Orthosis } \\
\text { (ABS) }\end{array}$ & 0.35 & $\begin{array}{l}\text { Rohringer } \\
\text { et al., }\end{array}$ \\
\hline & Skin & 0.48 & $\begin{array}{l}2019 \\
\text { Li et al., } \\
2012\end{array}$ \\
\hline & $\begin{array}{c}\text { Ground } \\
\text { Plate }\end{array}$ & 0.10 & $\begin{array}{l}\text { Cheung et } \\
\text { al., } 2005\end{array}$ \\
\hline \multirow{3}{*}{$\begin{array}{l}\text { Friction } \\
\text { Coefficient }\end{array}$} & $\begin{array}{l}\text { Skin- } \\
\text { Cast }\end{array}$ & 0.53 & $\begin{array}{l}\text { Vilhena et } \\
\text { al., } 2019\end{array}$ \\
\hline & $(\mathrm{ABS})$ & & \\
\hline & $\begin{array}{l}\text { Plate- } \\
\text { Cast } \\
\text { (ABS) }\end{array}$ & 0.30 & $\begin{array}{l}\text { Vilhena et } \\
\text { al., } 2019\end{array}$ \\
\hline
\end{tabular}

\section{RESULT AND DISCUSSION}

\section{A. Von Mises Stress}

Figure 5 and Figure 6 shows the contour plots of VMS distributions on both cast and skin with the maximum stress values are labelled. The point of view for the cast and leg only shows the bottom surface where most of the distinct and high stress occurred in this surrounding surfaces. The maximum VMS also were labelled on each leg for the different cast (Figure 6). The maximum values of VMS are inserted in the bar chart as shown in Figure 5b. From the findings, it is showed that toe off condition demonstrated the highest von Mises stress for both cast (213.12 MPa) and skin (0.496 MPa). The second highest was the heel strike condition with the maximum von Mises stress recorded at 106.99 MPa and $0.405 \mathrm{MPa}$ for cast and skin, respectively. Last but not least, the value for the midstance condition demonstrated lowest stress at 7.297 MPa (cast) and 0.125 MPa (skin). In terms of percentage difference for the cast model, the stress during the midstance phase is at $174.5 \%$ and $186.7 \%$ difference compared to heel strike and toe off condition, respectively. For the skin, the midstance condition give $105.7 \%$ and $119.5 \%$ difference as compared with heel strike and toe off condition, respectively.
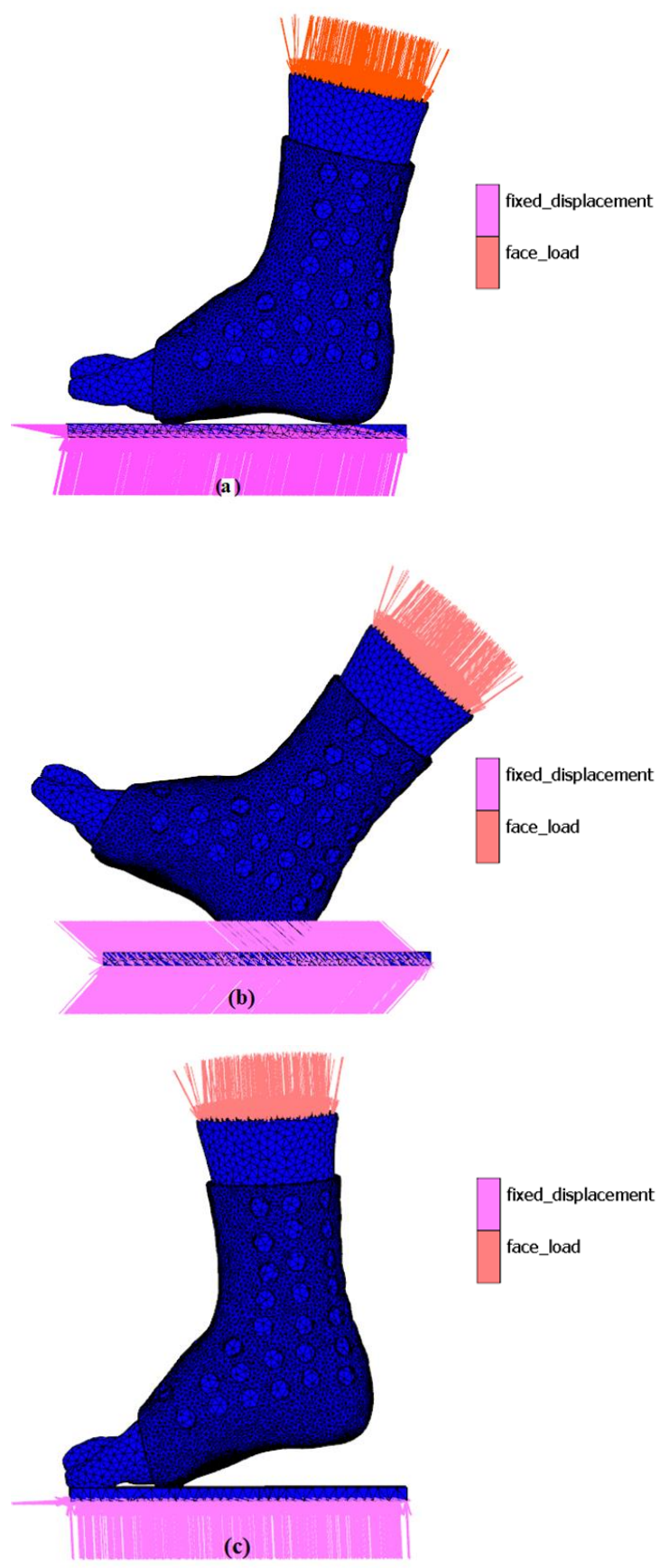

Figure 4. Boundary condition for (a) midstance phase, (b) heel strike and (c) toe off condition in a gait cycle 


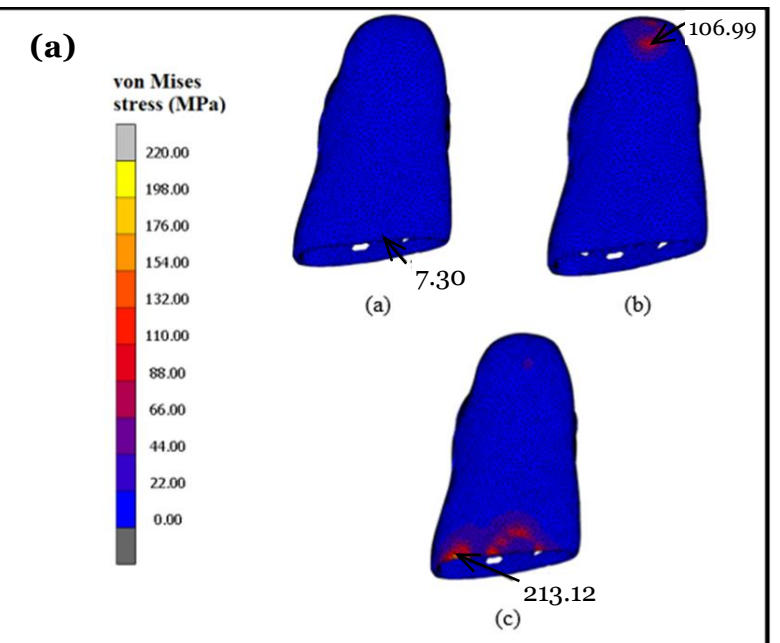

(b)

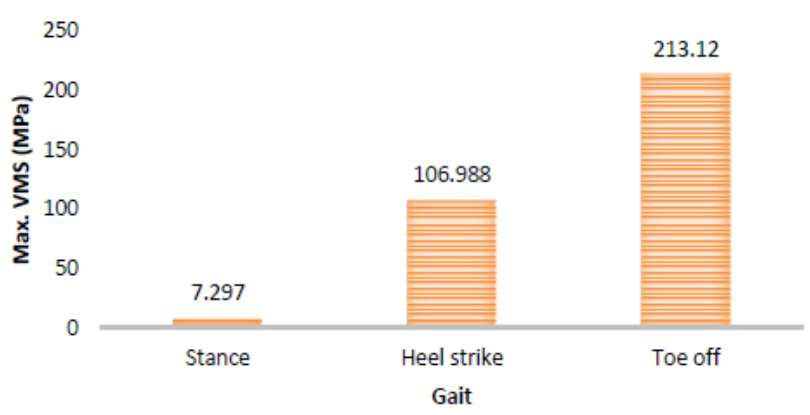

Figure 5. (a) Contour plot of von Mises stress and (b) maximum stress during midstance phase, heel strike and toe off condition, respectively.

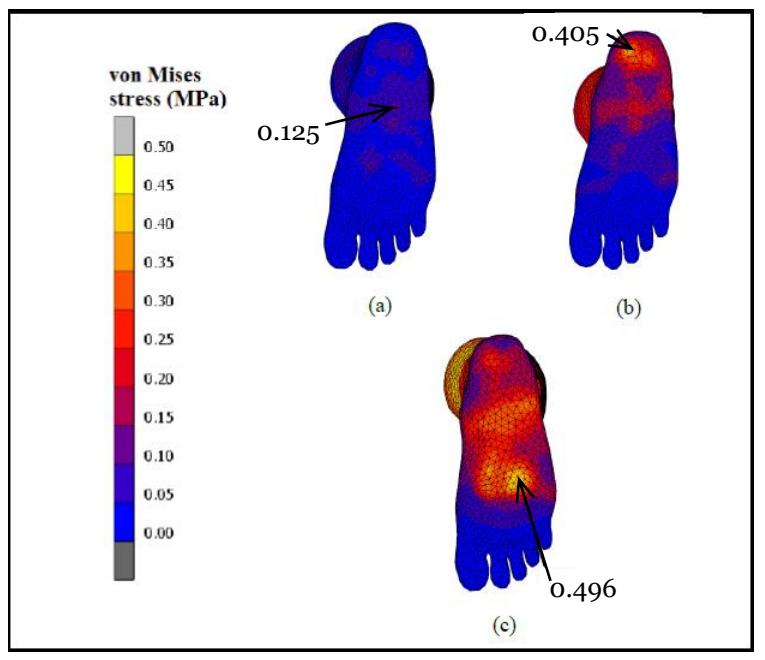

Figure 6. Contour plot of von Mises stress of skin for (a) midstance phase, (b) heel strike and (c) toe off condition in a gait cycle.

\section{B. Displacement}

Figure 7 shows the contour plots of diplacement distribution on both cast and skin for the three different gait phase. Again, the toe off had the highest value for the overall distribution with value of $68.15 \mathrm{~mm}$ (cast) and $79 \mathrm{~mm}$ (skin). For the heel strike, the overall displacement were $21.65 \mathrm{~mm}$ (cast) and 26.62mm (skin). Lastly, midstance phase showed the lowest displacements at $1.401 \mathrm{~mm}$ and $1.719 \mathrm{~mm}$ for the cast and skin, respectively. The difference of displacement values between the gait phase were quite large showing that different movement yields results.
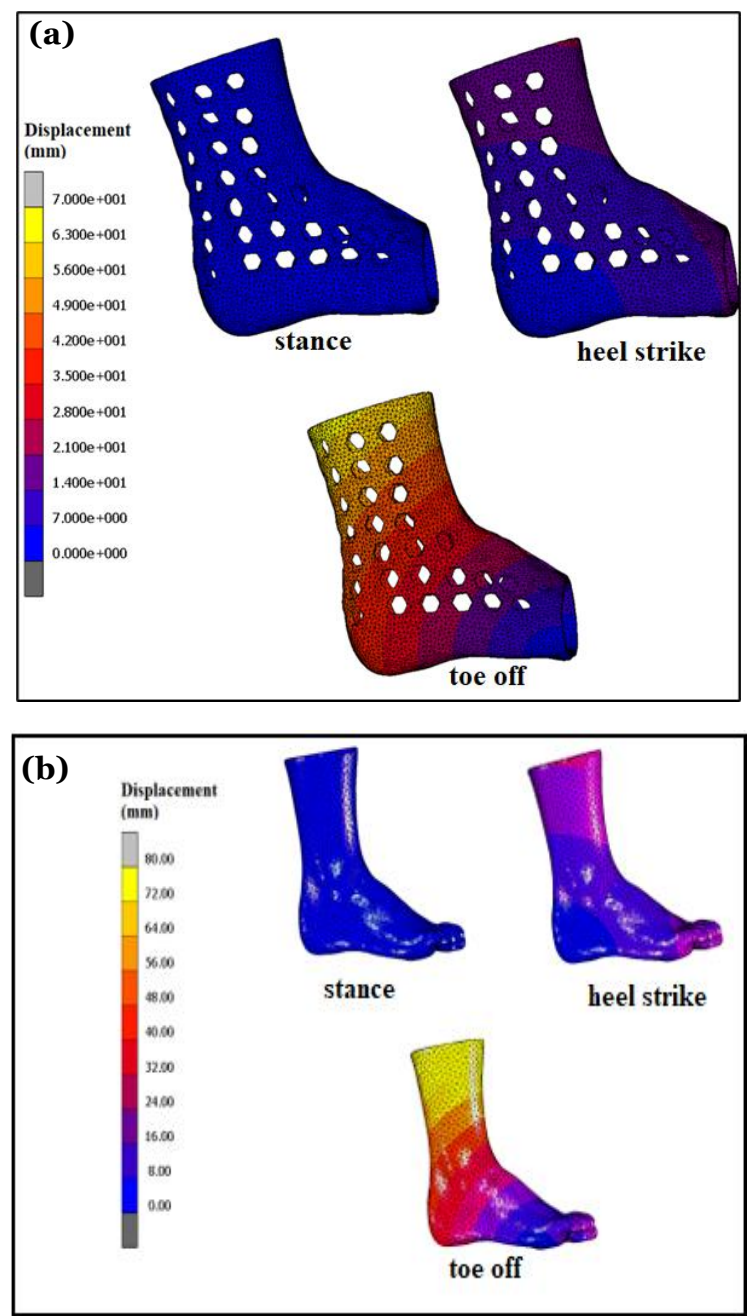

Figure 7. Contour plot of displacement for (a) leg cast and

(b) skin during midstance phase, heel strike and toe off condition, respectively.

\section{Discussion}

From the results, maximum von Mises stress (VMS) on the cast for heel strike and toe off were exceeding ABS yield strength. For the heel strike, the maximum VMS did beyond ABS 's yield strength (23MPa) but it lower than its ultimate tensile strength which is $110 \mathrm{MPa}$ (Ambrose et al., 2005). The value of VMS of the cast indicated that it had reached the yield 
strength and were considered failed. If the stress reach the value of ultimate tensile strength, then the cast will be fail. Hence, there is still possibility that it could be used for heel strike, however further experimental studies should be conducted to justify this findings. On the other hand, the maximum VMS on cast during toe off was exceeding the ultimate tensile strength, which indicates it is broken. Therefore, the cast is not recommended to be used in the toe off condition.

According to a previous study done by Lin $\mathrm{H}$ et al. the maximal stress are more likely concentrated in the area of edges of a hole on the cast which consider as a sharp corner (Lin et al., 2016). Same patterns of stress distribution occurred in this study where the concentrated stress illustrated at the edges of the hexagonal holes. A quite similar study done by Dal Maso et al. measured the maximum admissable stress by dividing the maximum stress measured by a safety factor of 2 (Dal Maso et al., 2019). The study also used midstance configuration and the results were from 10MPa and 22.5MPa considering that they only focused on a group of critical points (Dal Maso et al., 2019).

As far as authors are aware, from literature search, there are not much studies about the leg orthosis for treating fracture bone, especially in finite element analysis. A few literature regarding the finite element analysis of Ankle-Foot Orthosis (AFO). The recent study by Darwich et al. (Darwich et al., 2020), where they analysed the AFO in terms of stress distribution via finite element method and found that high stress of 14.6 MPa was demonstrated at the back side of the design. Another study by researchers from Belgium (Ielapi $e t$ al., 2019) in which they analysed two different designs of AFO in terms of von Mises stress. From the findings, they reported that high stress is also occurred at the back side of AFO with maximum value of $50 \mathrm{MPa}$. As compared with our design, the peak stress stress demonstrated at the distal part of orthosis. This might be due to the fact that of boundary condition of midstance, heel strike and toe off. Those two literatures mentioning different boundary conditions as compared with our analysis. Another point of view, the results from both papers are not same pattern with this study since the model of AFO is only covering the back side of the leg. As compared with our design, the $3 \mathrm{D}$ model of cast is wrapping all sides of the leg, therefore, it could possibly give enough strength to maintain its structure. Moreover, only those two are the related leg or ankle-foot orthosis studies that available from the literature. It is hoped that further studies could be conducted in the nearest future to investigate the effectiveness of leg orthosis in treating fracture bone.

Figure 7 shows that the displacement occurred on both skin and cast for heel strike and toe off were large and considered not safe to be used for that gait as compared to maximum allowable displacement value, $4.9 \mathrm{~mm}$ mentioned in a study done by other scholar (Lin et al., 2016). The study was on the $3 \mathrm{D}$ medical cast where they stated that displacement exceeding allowable value could lead to too loose fitting and failure to correct the limb distortion caused by fracture (Lin et al., 2016). There is also finite element analysis done by Chen Y et al. where the displacement of cast, bone and bone fracture were compared (Chen et al., 2020). Based on their results, it shows that different loading condition produces distinctly different output, with bone fracture displacements were ten times smaller than cast displacement. Therefore, the displacement of the cast in this study could be used to roughly estimate and predict the bone fracture displacement in the future.

Analysis of the gait phase study was conducted to observe the potential of the leg orthosis application for walking condition in which consist of the midstance, heel strike and toe off during rehabilitation period. It has been reported that interfragment micromoval at the fracture site was identified as an significant parameter that helps in the process of bone healing (Ramlee et al., 2014). There are factors that could be reconsidered from the result in this study which are the limitations on this study. Firstly, the amount of load applied was only considering the normal subject instead of a person with any ankle fracture. For a patient associated with fractured ankle, the amount of load would be much lower since he or she would carefully and slowly walks the injured leg. Next, this study only consider static analysis instead of dynamic analysis. The results produced were assuming the skin behave isotropic but in real life, it would behave anisotropic which is considered as one part of this study limitations. Another limitation of this study is the use of mesh size of $7 \mathrm{~mm}, 5 \mathrm{~mm}$ and $8 \mathrm{~mm}$ for leg, cast and ground plate, respectively. To be noted, those three values were automatically set by the 3 -matic software via adaptive 
meshing tool. The adaptive meshing tool could construct an optimum mesh size that suit with the geometrical shape and size of the $3 \mathrm{D}$ model without the need of mesh convergence and sensitivity analysis. Nevertheless, it is suggested that the nearest future studies could identify the best size of that particular $3 \mathrm{D}$ model via h-refinement or $\mathrm{r}$-refinement method.

\section{CONCLUSION}

In conclusion, the findings from the finite element analysis have revealed that $3 \mathrm{D}$-designed leg cast could sustain a load from midstance phase, rather than heel strike and toe off in terms of stress distribution and displacement. It yields acceptable value of stress and displacement at both cast (7.297 $\mathrm{MPa}$ ) and skin (0.125 $\mathrm{MPa}$ ) which far smaller compared to their yield strength (23 MPa). From this study, it is hoped that the findings could become a benchmark reference in the nearest future studies on the leg cast design.

\section{ACKNOWLEDGEMENT}

The authors would like to thank all students and staffs from the School of Biomedical Engineering and Health Sciences, Faculty of Engineering, Universiti Teknologi Malaysia for their endless supports to finish this research project. Special thanks to the Medical Devices and Technology Centre (MEDITEC), Institute for Human Centered Engineering (iHumen) for providing special facilities and equipment such as power computer, CT dataset, data analysis system and simulation software. This research was supported by Ministry of Higher Education Malaysia under Fundamental Research Grant Scheme (FRGS) (Grant no.: FRGS/1/2019/TKo5/UTM/02/3 and 5F135), Universiti Teknologi Malaysia under Tier 2 research grant (Grant no.: 15J84) and matching grant (Grant no.: 02M69), and Universiti Kuala Lumpur under Collaborative Research Grant Scheme (CRGS) (Grant no.: 4B618).

\section{REFERENCES}

Ambrose, K 2005, 'Materials testing', Emergency Nurse, vol. 13 , no. 6 , pp. 10.

Bu, Y, Li, Z, Liu, J, Wang, H, Raabe, D \& Yang, W 2019, 'Nonbasal slip systems enable a strong and ductile hexagonal-close-packed high-entropy phase', vol. 122, pp. 075502.

Chen, Y, Lin, H, Yu, Q, Zhang, X, Wang, D, Shi, L, Huang, W \& Zhong, S 2020, 'Application of 3D-printed orthopedic cast for the treatment of forearm fractures: Finite element analysis and comparative clinical assessment', Biomed Research International, eCollection 2020.

Cheung, JTM, Zhang, M, Leung, AKL \& Fan, YB 2005, 'Threedimensional finite element analysis of the foot during standing - A material sensitivity study', Journal of Biomechanics, vol. 38, pp. 1045-1054.

Choo, YJ, Boudier-Reveret, M, Chang, MC, 2020, '3D printing technology applied to orthosis manufacturing: narrative review', Annals of Palliative Medicine, vol. 9, no. 6, pp. 4262-4270.

Ekwall, A, Carlberg, E, Palmberg, G \& Sloberg R 2018, 'An audit of complications of fiberglass cast and hybrid cast for fractures of the foot, ankle and forearm in a Swedish emergency department', International Journal of Orthopaedic Trauma and Nursery, vol. 31, pp. 32-34.

Dal Maso, A \& Cosmi, F 2019, '3D-printed ankle-foot orthosis: A design method', Materials Today Proceedings, vol. 12, pp. 252-261.

Darwich, A, Nazha, H, Sliman, A \& Abbas, W 2020, 'Anklefoot orthosis design between the tradition and the computorized perspective', International Journal of Artificial Organs, vol. 43, no. 5, pp. 354-361.

Guo, Y, Zhang, X \& Chen, W 2009, 'Three-dimensional finite element simulation of total knee joint in gait cycle', Acta Mechanica Solida Sinica, vol. 22, no. 4, pp. 347-351.

Graham, J, Wang, M \& Frizzel, K 2018, 'Conventional vs 3dimensional printed cast wear comfort', Hand, vol. 15, no. 3, pp. 388-392.

Ielapi, A, Lammens, N, Paepegem WV, Forward, M, Deckers, JP, Vermandel, M \& De Beule, M 2019, 'A validated computational framework to evaluate the stiffness of $3 \mathrm{D}$ printed ankle foot orthoses', Computer Methods in Biomechanics and Biomedical Engineering, vol. 22, no. 8, pp. $880-887$.

Lal, $\mathrm{H}$ \& Patralekh, MK, 2018 ' $3 \mathrm{D}$ printing and its applications in orthopaedic trauma: A technological 
marvel', Journal of Clinical Orthopaedic Trauma, vol. 9, no.

3, pp. 260-268.

Li, C, Guan, G, Reif, R, Huang, Z \& Wang, RK 2012, 'Determining elastic properties of skin by measuring surface waves from an impulse mechanical stimulus using phase-sensitive optical coherence tomography', vol. 9, no. 70, pp. 831-841.

Lin, H, Shi, L \& Wang, D 2016, 'A rapid and intelligent designing technique for patient-specific and $3 \mathrm{D}$-printed orthopedic cast', 3D Printing in Medicine, vol. 2.

Osmata, M, Palousek, D, Navrat, T \& Rosicky, J 2012, 'Finite element analysis for the evaluation of the structural behaviour, of a prosthesis for trans-tibial amputees', Medical Engineering \& Physics, vol. 34, no. 1, pp. 38-45.

Pawlaczyk, M, Lelonkiewics, M \& Wieczorowski, M 2013, 'Age-dependent biomechanical properties of the skin', Postepy Dermatologii i Alergologii, vol. 30, no. 5, pp. 302306.

Ramlee, MH 2015, 'Biomechanical evaluation and new improvement on Ankle', Penerbit UTM.

Ramlee, MH, Abdul Kadir, MR, Murali, MR \& Kamarul, T 2014, 'Finite element analysis of three commonly used external fixation devices for treating Type III pilon fractures', Medical Engineering \& Physics, vol. 36, no. 10, pp. 1322-1330.

Singh, R, Kamal, T, Roulohamin, N, Maoharan, G, Ahmed, B \& Theobald, P 2014, 'Ankle fractures: A literature review of current treatment methods', Open Journal of Orthopedics, vol. 4, pp. 292-303.

Stranding, S 2009, 'Gray's anatomy', 4oth edn, Churcill Livingstone.

Scoot, AM 2010, 'Diagnosis and treatment of ankle fractures', Radiologic Technology, vol. 81, no. 5, pp. 457-475.

Vilhena, LM \& Ramalho, A 2019, 'Friction behavior of human skin rubbing against different textured polymeric materials obtained by a $3 \mathrm{D}$ printing microfabrication technique', Tribology Transaction, vol. 62, pp. 324-336.

$\mathrm{Xu}$, R, Wang, Z, Ma, T, Ren, Z \& Jin, H, 'Effect of 3D printing individualized ankle-foot orthosis on plantar biomechanics and pain in patients with plantar fasciitis: A randomized controlled trial', Medicini Science Monitor, vol. 21, no. 25, pp. 1392-1400.

Zhang, X, Fang, G, Dai, C, Verlinden, J, Wu, J, Whiting, E \& Wang, CCL 2017, 'Thermal-comfort desgin of personalised casts', Proceedings of the 3oth Annual ACM Symposium on User Interface Software and Technology, pp. 243-254. 